\title{
Comparison of rainfall and water requirement for rice during rice growing period in Kirtipur, Nepal
}

\author{
S. Aryal ${ }^{1,2^{*}}$ \\ ${ }^{1}$ Central Department of Environmental Science, Tribhuvan University, Kathmandu, Nepal \\ ${ }^{2}$ University of Southern Queensland and Australian Center for Sustainable Catchments, Toowoomba, Australia
}

\begin{abstract}
An experiment was conducted to estimate the crop water requirement of rice and to compare it with the amount of rainfall. Experiment was designed to estimate evaporation and evapotranspiration in cylindrical half cut mineral water bottles. Rice was planted in the bottles to estimate evapotranspiration. The amount of rainfall during the experiment period was recorded in the rain gauge station. The evaporation was highest in the month of September $(3.16 \mathrm{~mm} /$ day) and lowest in June $(2.56 \mathrm{~mm} /$ day $)$. The rate of evapotranspiration was in increasing order from June to September ranging from 3.43 $\mathrm{mm} /$ day in June to $19.57 \mathrm{~mm} /$ day for September. The crop water requirement was in increasing order reflecting more water demand with the increase in days after plantation and successive developmental stage of rice. The total amount of rainfall in the study area over study period (23rd June to 30th September, 2005) was $549.59 \mathrm{~mm}$. The total crop water requirement of rice for same period in the same area was $711.45 \mathrm{~mm}$. It showed that the rainfall during the study period was insufficient to meet the water demand for rice in the study area.
\end{abstract}

Key words: Crop water requirement, Evaporation, Evapotranspiration, Kirtipur, Rice

\begin{abstract}
Introduction
Freshwater scarcity is viewed by both scientists and politicians as the second most important environmental issue of the 21st century (UNEP, 1999). Water stress, hunger and poverty are correlated to each other (Falkenmark, 1986). The efficient and timely utilization of the available water can reduce hunger and poverty to some extent. Rainfed agriculture contributes majority of the world food supply and hence upgrading rainfed agriculture is another strategy of reducing world poverty. Though the amount of rainfall is much higher than required for many crops in rainfed field, uneven spatial and temporal distribution of rainfall has also created water shortage in many mountainous areas (Xing et al., 2008).

Nepal is an agricultural country having majority of its agricultural production from rainfed agriculture. The agriculture production, though, governed by a number of factors, irrigation is the very important in the country where most of the agricultural activities are governed by rain water. Recently, a technique called low-cost drip irrigation has been introduced in a few experimental sites of Nepal for expanding irrigation into rainfed areas, thereby increasing land productivity (Westarp et al., 2003).
\end{abstract}

*Corresponding author, email address: aaryalsuman@gmail.com
There is an increasing consensus in developing and disseminating water-saving technologies at spatial scales ranging from the field to irrigation system (Bouman et al., 2002). It is necessary to know the mechanism of the water loss from the soil for wise use of the available water. Water is lost mainly through evapotranspiration which in turn is affected by number of factors such as climates, crop types, characteristics of soil and even with the stage of plant. Experiment on the crop water requirement gives us the useful information for supplying amount of water for plant use and help to reduce wastage of water from the field by undertaking necessary precautions. Water required for plants consist of water required for assimilation, transpiration consuming water, evaporation and field leakage. Inadequate and uneven distribution of rainfall during the growth period of crop requires supply of additional water for plant use. This study aimed to estimate the crop water requirement of rice at Tribhuvan University's micro-catchment (rain fed rice field), Kirtipur, Nepal, during rice growing period. The study also compared the amount of rainfall at Kirtipur with crop water requirement for rice over the same period to examine whether the rainfall was sufficient to meet the crop water requirement in the area or not. 


\section{Materials and Methods}

The experiment was conducted at the Central Department of Hydrology and Meteorology, Tribhuvan University, Kirtipur, Kathmandu. The elevation of the study site is 1296 masl. The study site is characterized by typical monsoon climate with rainy summer and dry winter. Day temperature in summer rarely goes beyond $30^{{ }^{\circ} \mathrm{C}}$ and falls below $20{ }^{\circ} \mathrm{C}$ at night. But in winter (December to February), it ranges from $18{ }^{{ }^{\circ} \mathrm{C}}$ to $0{ }^{\mathrm{O}^{\prime}} \mathrm{C}$ at day and night respectively. Over $80 \%$ of total annul rainfall occurs during monsoon period. For most of the time of the year, the area near experimental site remains fallow due to lack of irrigation water. But during the summer season, rice is planted in the field using rain water.

\section{Experimental design and data collection}

Four cylindrical plastic bottles (mineral water bottles) of the same size were taken and cut down to almost half. The diameters of the bottles were measured. Each of the half cut bottles was filled with soil taken from TU field and water was gradually poured in the bottles. Two of them were planted with one month old three seeding of rice collected from farmer's field of the same area in each and the remaining two were left as such to record the evaporation. The seedings were transplanted in 23rd June, 2005.

The evaporation (from the bottles without rice plants) and evapotranspiration (from the bottles with rice plants) were recorded. For this, weight of each bottles were measured in the first day of the experiment and again after one or two days after first measurement. The loss in weight of bottles without rice was used to calculate evaporation and loss in weight of bottles with rice was used to calculate evapotranspiration. The amount of water loss (mass) from each bottle was converted into volume $\left(1 \mathrm{mg}=1 \mathrm{~mm}^{3}\right)$. Evaporation and evapotranspiration were obtained in height ( $\mathrm{mm}$ ) by dividing volume of water $\left(\mathrm{mm}^{3}\right)$ loss by the surface area of the bottles $\left(\mathrm{mm}^{2}\right)$. Amount of water was added in the bottles equal to their loss of weight observed again after one or two days. Similarly, the process was repeated till the spikelets of rice planted in the bottle were ripned (from 23rd June to 30th September, 2005).

The crop water requirement was calculated by adding the difference in evapotranspiration and evaporation for each of the observation. The crop water required for all observations within a month were added to calculate the crop water required for different month and finally all of those were summed to get crop water required for rice (from planting to maturity of seed). Amount of rainfall occurred during the experimental period was recorded for each observation from rain gauge station at the Central Department of Hydrology and Meteorology, Tribhuvan University, Kirtipur. The comparisons were made for water requirement of rice and amount of rainfall for each month and total duration of rice.

\section{Results}

\section{Evaporation and evapotranspiration}

Mean daily evaporation and evapotranspiration of rice plants was calculated for rice growing period. The evaporation was highest in September (3.62 mm/day) and lowest for June (2.56 mm/day). During July and August, it was $3.15 \mathrm{~mm} /$ day and $2.93 \mathrm{~mm} /$ day, respectively. The rate of evapotranspiration was in increasing order from June to September ranging from $3.43 \mathrm{~mm}$ /day for June to $19.57 \mathrm{~mm}$ /day for September (Table 1).

Table 1 Evaporation and evapotranspiration for different months

\begin{tabular}{lcc}
\hline Months & $\begin{array}{c}\text { Evaporation } \\
(\mathrm{mm} / \text { day })\end{array}$ & $\begin{array}{c}\text { Evapotranspiration } \\
(\mathrm{mm} / \text { day })\end{array}$ \\
\hline June & 2.56 & 3.43 \\
July & 3.15 & 5.16 \\
August & 2.93 & 8.21 \\
September & 3.62 & 19.57 \\
\hline
\end{tabular}

\section{Water requirement of rice}

The difference in the evapotranspiration and evaporation was considered as the water consumed by the rice plant and termed as crop water requirement. The crop water requirement was in increasing order reflecting more water requirement with increase in days after planting rice. At the beginning, when rice was transplanted, the crop water need was only $0.87 \mathrm{~mm} /$ day (June), but it gradually increased and reached to $15.95 \mathrm{~mm} /$ day (September) (Table 2). The highest amount of water required for rice was found in the month of September ( $478.5 \mathrm{~mm})$. 
Table 2 Crop water required for different months and amount of rainfall recorded over the same period

\begin{tabular}{lcccc}
\hline Months & No of days & Crop water required (mm/day) & Total crop water required (mm) & Rainfall (mm) \\
\hline June & 8 & 0.87 & 6.96 & 44.53 \\
July & 31 & 2.01 & 62.31 & 168.25 \\
August & 31 & 5.28 & 163.68 & 247.78 \\
September & 30 & 15.95 & 478.5 & 89.03 \\
\hline Total & & & $\mathbf{7 1 1 . 4 5}$ & $\mathbf{5 4 9 . 5 9}$ \\
\hline
\end{tabular}

\section{Comparison of crop water requirement and rainfall}

The total amount of rainfall at Kirtipur over the study period (23rd June to 30th September, 2005) was $549.59 \mathrm{~mm}$ (Table 2). The total crop water requirement of rice for the same period in the same area is $711.45 \mathrm{~mm}$ (Table 2). It showed that the total rainfall during the study period was insufficient to meet the water demand of rice at the Kirtipur.
The available water in the soil is mainly lost through evapotranspiration and moisture content in the soil determines the water available for evapotranspiration. The soil moisture content is also very important in calculation of water budget at the beginning of irrigation.

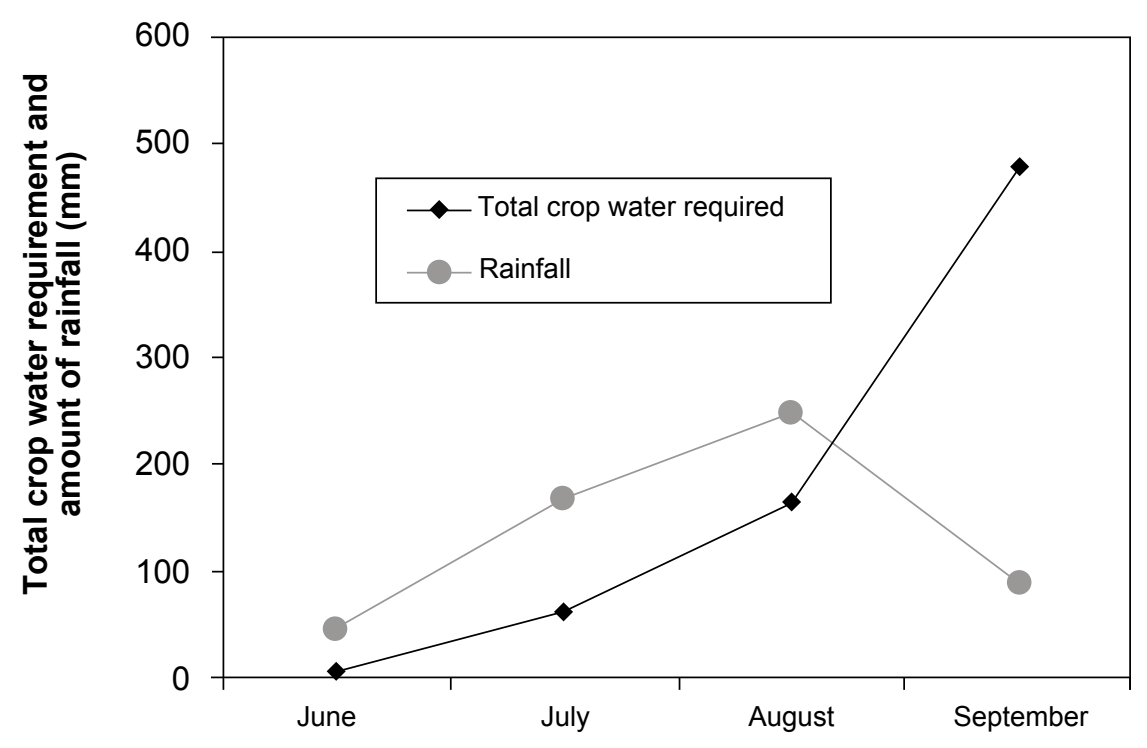

Fig. 1 Comparison of crop water requirement of rice and amount of rainfall for different months

\section{Month}

The total amount of the crop water requirement $(\mathrm{mm})$ and amount of rainfall $(\mathrm{mm})$ for different months were compared (Fig. 1). This showed that for first three months i.e. June, July and August, the total rainfall was higher than the water required for rice. But for last month i.e September, the amount of rainfall was lesser than the crop water required for rice.

\section{Discussion}

Evaporation and evapotranspiration are influenced by several climatic (sunshine, temperature, humidity, wind speed) and nonclimatic (soil type, rice varieties, stage of crop development, soil moisture characteristics etc.) factors.
In this experiment, the evaporation and evapotranspiration are higher for the month of the September. Higher values of the evapotranspiration can be attributed to the advancement in developmental stage of rice with high leaf area index. September being the month of flowering, spikelets formation, grain filling and finally ripening of the rice demanded more evapotranspiration. The lower value of the evaporation in June, July, and August may be govern by climatic factors. Since these months fall under peak monsoon season, high rainfall and high humidity in the atmosphere could have reduced the evaporation. 
The variation in the crop water requirement with the advancement in the development stage of the rice plants is reflected in this experiment. There is increase in the average daily crop water need of rice in the successive months. During the growing and developing stage crops need large quantity of water for various physiological functions. Sensitiveness of crop to moisture requirement changes with different growing and developing period. A certain crop grown in a sunny and hot climate needs more water per day as compared to a crop grown in a cooler and cloudy climate. Apart from sunshine and temperature, other climatic factors influence the crop water need. Same crops grown in different climatic zones may have different water needs. A certain maize variety grown in a cool climate will need less water per day than the same maize variety grown in a hotter climate (Smith, 2000). The water requirement of rice obtained in this experiment is higher than potential crop water requirement of rice i.e. $532 \mathrm{~mm}$, but the average input of the water applied is much higher than this level in many cases (Jehangir et al., 2007). This indicate that the water seepage and leakage from the rice field. The overall insufficient amount of rainfall to meet the demand of rice is due to large difference in crop water required and rainfall for the month of September.

\section{Conclusion}

The comparison of water requirement of rice and the amount of rainfall indicated that the rainfall was insufficient in the final stage (September) of the rice growing period in the study area i.e. TU micro-catchment. This period is very sensitive because important phenological events like flowering, spikelets formation, grain filling and ripening occur during this period. If these events are affected due to water shortage, rice production declines significantly. Though, the main agricultural crop at TU micro-catchment is rice, no attempts were made to estimate water requirement for rice and variation in water requirement in different stage of rice crop. The results of this study may help in planning of efficient water management and ultimately helps in increasing the efficiency of available water.

\section{Acknowledgements}

I am thankful to the Central Department of Hydrology and Meteorology, Tribhuvan University for providing equipments and the laboratory facilities for the study. I am thankful to Mr. Narayan Prasad Gaire and Mr. Yub Raj Dhakal for theirs cooperation during data collection. I am also thankful to the annonymous reveiwers for providing valuable suggestions and comments that strengthen the quality of the manuscript.

\section{References}

Bouman, B.A.M., Hengsdijk, H., Hardy, B., Bindraban, P.S., Tuong, T.P., \& Ladha, J.K. (2002, April). Water-wise rice production. Proceedings of the international workshop on water-wise rice production. Los Baños, Philippines, International Rice Research Institute.

Falkenmark, M. (1986). Fresh water-time for a modified approach. Ambio, 15, 192-200.

Jehangir, W.A., Masih, I., Ahmed, S., Gill, M.A., Ahmad, M., Mann, R.A., Chaudhary, M.R., Qureshi, A.S., \& Turral, H. (2007). Sustaining crop water productivity in rice-wheat systems of South Asia: A case study from the Punjab, Pakistan. Colombo, International Water Management Institute.

Smith, M. (2000). The application of climatic data for planning and management of sustainable rainfed and irrigated crop production. Agricultural and Forest Meteorology, 103, 99-108.

United Nations Environment Programme (UNEP) (1999). Global environmental outlook 2000.

Westarp, S.V., Chieng, S., \& Schreier, H. (2003). A comparison between low-cost drip irrigation, conventional drip irrigation, and hand watering in Nepal. Agricultural Water Management, 64, 143-160.

Xing, M., Jianchu, X., \& Jie, Q. (2008). Water resource management in a middle mountain watershed. Mountain Research and Development, 28, 286-291. 